\title{
Olhe pra mim de novo: um road movie documental sobre diversidade cultural/sexual
}

\author{
Wilton Garcia*
}

Resumo: Este texto apresenta uma discussão sobre diversidade cultural/sexual no Brasil a partir do filme Olhe pra mim de novo (Claudia Priscilla e Kiko Goifman, 2010). Trata-se de um road movie documental a respeito do transexual Syllvio Luccio. Das (re)dimensões teóricas e políticas resultam problematizações da produção de conhecimento acerca de corpo, gênero, identidade e performance que se encontram inseridas nos estudos contemporâneos do cinema e do audiovisual.

Palavras-chave: road movie documental; diversidade cultural/sexual; estudos contemporâneos.

Resumen: Este texto presenta una discusión sobre la diversidad cultural/sexual en Brasil desde la película Olhe pra mim de novo (2010), de Claudia Priscilla y Kiko Goifman. Se trata de una road movie sobre el transexual Syllvio Luccio. De las (re)dimensiones teóricas y políticas resultan problematizaciones de producción de conocimiento sobre el cuerpo, el género, la identidad y el desempeño que se insertan en los estudios contemporáneos del cine y el audiovisual.

Palabras clave: documental road movie; diversidad cultural/sexual; estudios contemporáneos.

Abstract: This paper presents a discussion of cultural/sexual diversity in Brazil from the film Olhe pra mim de novo (2010), by Claudia Priscilla e Kiko Goifman. It is a road movie documentary about the transgender Syllvio Luccio. From the theoretical and political dimensions results the problematization of knowledge production about body, gender, identity and performance that are inserted in contemporary studies of cinema and audiovisual.

Keywords: road movie documentary; cultural/sexual diversity; contemporary studies.

Résumé: Cet article présente une discussion sur la diversité culturelle/sexuelle au Brésil à partir du film Olhe pra mim de novo (Claudia Priscilla et Kiko Goifman, 2010). Il s'agit d'un road movie documentaire sur le transgenre Syllvio Luccio. De la (re)dimension théorique à celle politique, il en résulte la question de la production de connaissances sur le corps, le sexe, l'identité et la performance dans la proposition des études contemporaines du cinéma et de l'audiovisuel. Mots-clés: road movie documentaire; diversité culturelle/sexuelle; études contemporaines.

* Universidade de Sorocaba, Programa de Pós-Graduação em Comunicação e Cultura, Grupo de Pesquisa Mídia, Cidade e Práticas Socioculturais.18.023-000, Sorocaba/SP, Brasil. E-mail: wilton.garcia@prof.uniso.br.

$\mathrm{O}$ presente texto faz parte da pesquisa Imagem, cultura e diversidade: estudos contemporâneos, em andamento.

Submissão do artigo: 04 de dezembro de 2015. Notificação de aceitação: 13 de fevereiro de 2016.

Doc On-line, n. 19, março de 2016, www.doc.ubi.pt, pp. 187-200. 
O consumo de sexo passa pela garganta estreita dos padrões "vendáveis" no mercado da carne, em clima de competição baseado no exibicionismo.

(Trevisan, 2000: 471)

Hoje, a expressão da carne/corpo para consumo emerge como reflexo de erótica, desejo, sensualidade e/ou sexo, sobretudo no âmbito do cinema e do audiovisual. Notadamente, o que se observa no mercado-mídia são os enfrentamentos cotidianos que equacionam a lógica contemporânea projetada pelo impacto vertiginoso do capital. De modo antropofágico, corpos expostos em cena aguçam o(a) espectador(a). E sua performance estimula feixes de efeitos de sentidos. A crescente exposição da intimidade, sem manter sigilo algum, atravessa o privado e o público em espetacularidade (Vargas Llosa, 2012). Mas, também realiza um convite à reflexão, ao conclamar uma posição de mundo. Na epígrafe deste texto, o autor faz uma crítica ácida à exibição do sexo e amplia os parâmetros da diversidade cultural/sexual.

A intensidade desse panorama descrito acima, serve para introduzir uma leitura sobre o documentário brasileiro Olhe pra mim de novo (2010), dirigido por Claudia Priscilla e Kiko Goifman. Esta fita exibe uma narrativa documental densa (dura e cruel), quando expõe as dificuldades do protagonista transexual Syllvio Luccio, em particular no espaço conservador do Nordeste brasileiro. Ao longo do texto, imagem, experiência e subjetividade são categorias enunciadas como estratégias discursivas, a elaborar perspectivas criativas e políticas de visibilidade e ação afirmativa para o universo Trans.

$\mathrm{Na}$ tela, configuram-se situações complexas que afrontam a natureza humana. A leitura que aqui se organiza são impressões e registros de uma potencial exemplificação fílmica (Garcia, 2013), a se (des)dobrar em elementos conceituais e teóricos da diversidade cultural/sexual no cinema nacional contemporâneo. Para Lúcia Nagib (2012: 28), "novas ferramentas teóricas são necessárias para entender a relação entre sexo e poder no cinema [...] um mundo pós-diferença, onde noções de normalidade comumente usadas para definir um 'outro' deixaram de existir". Isso requer uma flexibilidade críticoconceitual necessária a qualquer pesquisador(a)/investigador(a), a (re)formular a dinâmica de variáveis discursivas entre alteridade, diferença e diversidade. Mais que isso, aspectos econômicos, identitários, socioculturais e políticos estabelecem determinado agenciamento/negociação para se indagar a respeito da sociedade contemporânea.

Assim, instaura-se uma pergunta: como refletir acerca desse tipo de produção audiovisual - o documentário - quando tange a diversidade cultural/sexual no Brasil? 
Tal questão assume contornos específicos do contexto observado conforme (re)dimensiona a sociedade atual e suas interrelações em Olhe pra mim de novo. Um documentário desafia espectadores(as), intelectuais e políticos para dar encaminhamentos às manifestações e aos possíveis avanços da humanidade. Por exemplo, a desigualdade social no Brasil e no mundo formula considerações proeminentes e pontos de vista estratégicos que acompanham a atualização de discursos, dispositivos e tendências, inscritos no sustento da atmosfera contemporânea. De alguma maneira, alternativas estéticas, científicas e/ou políticas tentam equiparar as vastas desigualdades em contraponto aos substratos do consumo (Bauman, 2013).

Para se (re)pensar uma dimensão teórica, elejo os estudos contemporâneos. Trata-se de uma área interdisciplinar que associa os estudos culturais - e suas variantes multiculturais, pós-coloniais e diaspóricas (Cevasco, 2003; Eagleton, 2012; Hall, 2003, 2002) - às tecnologias emergentes (Canclini, 2008). Os estudos contemporâneos tentam constituir uma teoria social e política ao desdobramento de reflexões, em especial no campo da comunicação, inclusive do cinema. Assim, qualquer proposição binária (centro/periferia, hegemônico/subalterno, opressor/oprimido ou tradicional/moderno) torna-se ineficaz, bem como reduz as abordagens. Tais estudos atualizam a cooperação de assuntos como: globalização, ecologia, empreendedorismo, neoliberalismo, sustentabilidade. O escopo, dessa forma, concentra-se na discussão teórica e prática sobre responsabilidades socioculturais, políticas e identitárias (Hall, 2003, 2002), sem necessariamente se apreender como propriedade enunciativa.

Isso pressupõe que a noção de contemporâneo - para além da previsão temporal, cronológica - ultrapassa as parcelas do tempo (passado, presente e futuro), ao indicar uma reflexão baseada em atualização e/ou inovação. Atualizar/inovar faz parte do acompanhamento e acomodação dessa noção como estado deslizante e intermediário, que comporta provisoriedades e parcialidades. Tanto os aparatos das tecnologias emergentes, em seus ferramentais, quanto as escolhas estéticas e éticas, em suas tendências, passam a compor estratégias discursivas e seus respectivos paradoxos.

Realizadas as inscrições introdutórias, proponho dois tópicos - um road movie documental e diversidade cultural/sexual. Essa divisão pretende aquecer o debate por ora anotado. Do objeto de investigação ao tema em questão, emergem tópicos distintos que se complementam e se aglutinam como prioridades a respeito dos recursos oferecidos. 


\section{Um road movie documental}

A condução de estratégias discursivas em um documentário traduz qualquer evento em encenação: o atuar. A partir de um filme, o(a) espectador(a) relaciona realidade e ficção no ambiente em que convergem a experiência e seu referente (Peixoto, 2007). Esse encontro tange o estado vivenciado pelo suposto personagem e o audiovisual captado por recursos tecnológicos. No desafio de instabilidades - perante o acaso, o inesperado, o imprevisto e/ou o improviso - tal documentar visa à artimanha de determinado cálculo no planejamento cinematográfico, o qual permite colocar-se no lugar do(a) outro(a): a empatia de alteridade, diferença e diversidade.

Olhe pra mim de novo elabora um misto de road movie e documentário, ao exibir a história de Syllvio Luccio. Como transexual masculino, esse sujeito surge fora do eixo hegemônico, o que pode instaurar a ocorrência de um road movie. Eis um elevado movimento transitório que se articula pelos fatos registrados, aos poucos, em deslocamentos espaciais. De acordo com Claudia Marinho,

O espaço é construção e se mostra como produto das vivências dos sujeitos que deslocam seus corpos pelos lugares e não-lugares moldando roteiros, nem sempre precisos. Essa experiência de espaço informa os contextos, moldando paisagens que são produtos das percepções, memórias, subjetivações individuais e coletivas. (Marinho, 2007: 228).

As coisas acontecem na tensão do espaço. Nesse trânsito, verifica-se a condição humana do protagonista, cuja ambiguidade de gênero (masculino x feminino) é recorrente. Sozinho, na estrada, o personagem afirma que gostaria de fazer a cirurgia de mudança de sexo, uma vez que se vê preso em um corpo que não lhe pertence. Na tela, a estrada representa uma solução: a saída contra o sistema. Syllvio diz que não pretende padecer em um corpo de mulher. Com metáfora, sente-se confinado em uma gaiola. Isto é, evita a forma corporal atual, a qual não expressa sua identidade sexual e de gênero. Diante de tamanha provação, não desanima, pois se reinventa ao admitir uma masculinidade "exótica". E, nesse momento, vale lembrar sua posição social como ativista militante a se destacar em prol das causas das comunidades Lésbicas, Gays, Bissexuais e Transexuais (LGBT) e afins. Em busca da felicidade, faz desse percurso uma exploração de si. A sinopse indica:

Um road movie no sertão do Nordeste brasileiro. Nesse cenário - marcado pelo forte calor, pela pobreza e pela cobrança extrema da virilidade do homem - Syllvio Luccio é um transexual masculino em fase de transformação.

O que caracteriza um road movie - filme de estrada - são as passagens por diferentes cidades e estradas, com o desenrolar da trama acontecendo ao longo 
de determinada trajetória. No campo dos estudos de cinema (Ramos, 2005), road movie é reconhecido como gênero fílmico em que situações insurgentes são ressaltadas como problemas a serem solucionados, ou não, diante de conflitos e obstáculos. Seria, metaforicamente, o flaneur de Baudelaire associado à presença de um andarilho que almeja atravessar o mundo observando detalhes. Durante a viagem, acontecimentos acrescentam-se à cinemática, a compreender desfechos inimagináveis pelo(a) espectador(a), do ponto de vista da recepção. Samuel Paiva (2007: 176) escreve: "o road movie é um gênero quase que exclusivamente focado nos homens, promovendo uma fantasia que vincula masculinidade e tecnologia como resistência às responsabilidades do mundo doméstico, ao casamento, ao emprego fixo". E o transcorrer da história depende de decisões de envolvidos(as), a (re)conduzir desafios.

Em uma das passagens do documentário no decorrer da viagem, Syllvio Luccio encontra um grupo de gays e transexuais à noite em uma praça na cidade de Currais Novos, pequeno lugarejo do Rio Grande do Norte. Conversando com eles, recebe uma pergunta curiosa de um rapaz, Eneus: "Porque eu pensava que você era um homem, que pegou... que tirou e agora quer voltar a ser homem de novo. (risos). Mas, você vai botar um pênis ou já botou?" A imediata resposta do transexual foi: "Me dê sua mão... não, aqui". E levou a mão do jovem rumo à cintura do seu corpo Trans. E a confirmação, como réplica por parte de Eneus, foi em tom de brincadeira: "Ai, que delícia... (risos) chibocudo, eh! Ai, adorei. Chibata tá boa (risos)".

$\mathrm{Na}$ brincadeira, o contato físico surpreendeu a expectativa do rapaz. Sua desinformação aponta para a necessidade do cinema trazer para cena esse tipo de temática sobre a diversidade. A simplicidade do lugarejo que Eneus ocupa acaba por definir seus breves limites. $\mathrm{O}$ acesso à informação permite determinado conjunto de fatores que acenam determinada realidade. E o documentário provoca essa experiência de ampliar as possibilidades, ao contribuir com o sujeito.

Para Norval Baitello Jr. (2012: 37), "quem anda muito não pode carregar muitas coisas, pois estas travam a mobilidade, impedem o deslocamento, roubam a agilidade e a prontidão". Essa economia de materiais reflete a economia do saber. Portanto, é algo instável, passageiro, como condição adaptativa de Ser/Estar do sujeito em trânsito - em constante circulação. Em sua múltipla versatilidade constitutiva de início e/ou fim, a trajetória de uma estrada traz mudanças com deslocamentos que podem ser radicais.

$\mathrm{Na}$ extensão de dois ou mais pontos, a estrada efetiva paisagens, pois o deslocar revela surpresas, visto que a passagem por diferentes lugares se transforma. Olhe pra mim de novo solicita da plateia outro olhar, mais atento, pro- 
fundo. No trajeto do protagonista fomenta-se um intercâmbio de informações com os demais personagens da narrativa; o roteiro incorpora situações diferentes, por etapas, que complexificam a condição humana com elementos da ideia de diversidade cultural/sexual. O que faz emergir um sujeito diferente, estranho talvez, porque não é comum (Sodré, 2014). Tal estranhamento impacta o público acostumado a lidar com a norma.

Nesse documentário, o(a) espectador(a) acompanha cada rota e tenta se acomodar diante dos fatos que surgem na tela, implementando o debate acerca da diversidade. A singularidade do protagonista aponta para uma produção de presença (Gumbrecht, 2010), mediante a instabilidade que assola a paisagem nordestina no país. O corpo transexual, em trânsito, indicia o fluxo de possibilidades de identidade de gênero. Grosso modo, o documentário vetoriza um ar eloquente da narrativa, como se fosse uma reinauguração de cada cena em si.

Aqui, o road movie está em consonância com o formato documental, tomando a história de Syllvio Luccio como personagem central da trama e o registro audiovisual da realidade transexual. O roteiro atravessa diversos espaços e estágios que comportam o sertão do Nordeste brasileiro, passando os estados do Ceará, Rio Grande do Norte, Paraíba e Pernambuco. Uma região árida, (de)marcada por forte seca, calor, miséria e pobreza, dificulta a sobrevivência.

Situações críticas de sobrevivência diante de atropelos e adversidades estabelecem a condição adaptativa do sujeito ao mundo. Cada sujeito com sua experiência tenta sobreviver às emoções de suas dificuldades no conviver com o(a) outro(a) e, propriamente, consigo. Isso sedimenta/chancela denúncias de sobrevivência do Ser Humano. Ou seja, esforça-se para assistir uma voz da diferença na sociedade. Tal situação de deslocamento incessante (re)desenha certa postura política de sobrevivência como resposta ao esgotamento atual. De acordo com Peter Pelbart,

A condição de sobrevivente é um efeito generalizado do biopoder contemporâneo; ele se restringe aos regimes totalitários e inclui plenamente a democracia ocidental, a sociedade do consumo, o hedonismo de massa, a medicalização da existência, em suma, a abordagem biológica da vida numa escala ampliada. (Pelbart, 2013: 26-27).

Retomando: na medida em que se constitui uma relação entre sujeito e personagem, a interseção do plano da narrativa cinematográfica dialoga com a realidade captada pela câmera e tenta formalizar um estado intermediário acerca da exploração geográfica inscrita nesse road movie documental. Para Gustavo Souza,

O road movie é um tipo de filme cuja história se passa na estrada. De fato, não há novidade nessa constatação, mas não se pode esquecer que as ações 
na estrada, durante a viagem, são encabeçadas pelos personagens. Logo, se o personagem não se desloca, não há narrativa, não há história, não há road movie. Daí a importância de pensar o personagem no âmbito do road movie documental como uma instância particular do mundo histórico e com relação a ele próprio. (Souza, 2015: 6).

Compreendida como lugar de chegada, partida e trânsito, a estrada (re)vela mudanças com deslocamentos que podem ser, inclusive, radicais, uma vez que projetam traços que se (des)cortinam na vida. O que efetiva uma interação de espaços entrecruzados - um território provisório, intermediário. A imagem da estrada no cinema exibe-se com profundidade seletiva como jornada de desbravamentos, combates e/ou conquistas. Segundo Francisco Elinaldo Teixeira

A paisagem documental atual não se ergue num horizonte canônico único, mas numa multiplicidade sem precedentes de formas, certamente como algo que se deixou afetar e abriu passagens por entre as tantas ondulações e revoluções da cultura audiovisual contemporânea. (Teixeira, 2004: 19).

No registro do mundo, um estado intermediário entre ficção e realidade agencia/negocia um ar intersubjetivo no tecido social. Documentar, atravessar a realidade com uma câmera é se esforçar para traduzir o mundo em imagem e som. O que está na cena destaca-se no ato de observar com diferentes desdobramentos crítico-conceituais. Então, o road movie documental torna-se elástico ao convergir forças e vetores. Uma história de vida se tranforma quando a experiência da estrada oferece "novas/outras" possibilidades. Os enunciados de qualquer filme documentário, nesse caso, correlacionam-se com recursos técnicos e estilísticos.

Portanto, observar é mais que atentar, constatar, examinar, fitar, mirar, notar, perceber, presenciar, reparar, testemunhar, verificar ou, até mesmo, documentar e registrar. Observar seria absorver o que se encontra diante de qualquer observador(a). Evidentemente, isso faz parte do processo de elaboração de determinada produção de conhecimento, o qual constitui derivativas de um documentário como gênero cinematográfico (Teixeira, 2004), a explorar traços intersubjetivos do ato observado.

\section{Diversidade cultural/sexual}

Durante o curso desse road movie documental, Syllvio Luccio caminha solitariamente. $\mathrm{O}$ trajeto parece adentrar por retas e curvas, altos e baixos, nas estradas desertas do semiárido brasileiro. A narrativa cinematográfica ocupa o espaço do personagem enquanto construto de uma figura metafórica em um quase vazio existencial: a experiência do Eu intrínseco, profundo. O transtorno 
de identidade sexual e de gênero trilha seu destino esfacelado entre veredas e alamedas, sem abundâncias.

No entorno de ações surpreendentes entre performatividade e audiovisual, trata-se de um recorte instigante, porque propicia visibilidade e ação afirmativa para o debate estético, conceitual e crítico sobre a diversidade cultural/sexual no Brasil e no mundo. Hoje, se mostrar - na contramão do código hegemônico - faz parte de uma estratégia política para estar na cena do universo Trans. É uma diferença brutal.

A diversidade, agora, emerge como iniciativa de luta e combate acerca de alteridade e diferença na extensão de identidades (sexual e de gênero). Há variáveis inimagináveis na vida. Tal diversidade tenta driblar o mundo, literalmente, com variantes que ultrapassam o discurso hegemônico e serve de contraponto para agenciar e negociar a exclusão de termos e expressões subalternas. Isso convoca certo posicionamento teórico-político capaz de estabelecer uma relação da teoria com a prática, ao ponderar aspectos econômicos, identitários, socioculturais e políticos.

Nesse filme, ciência e religião conduzem suas próprias estratégias discursivas, ao colocar em xeque a sociedade contemporânea, em particular as minorias sexuais. Entre paradoxos e contradições, observam-se transversalidades dessa narrativa contundente que enuncia um personagem mulher. Syllvio primeiro engravidou e foi mãe. Depois, teve amores e vivências homoeróticas. A partir disso, pretende alcançar a transexualidade. Portanto, nasceu mulher, vivenciou a maternidade, tornou-se lésbica e, para arremate, quer ser homem.

Para completar, os gêneros discursivos aqui se misturam para além de uma lógica binária - masculino/feminino - insuficiente à expressão dinâmica que abarca o idioma da língua portuguesa. A gramática normativa atual, assim, não consegue acomodar as nuances da diversidade cultural/sexual que orienta a projeção identitária, linguística, sociocultural e política de determinadas circunstâncias especiais, as quais permeiam comunidades LGBT e afins. Ou seja, esse road movie faz urgir uma voz da diferença a documentar os fluxos da diversidade.

O que caracteriza a diversidade cultural/sexual como estratégia de subjetividade no produto audiovisual brasileiro são os tipos multiformes que circundam a expressão LGBT no país. Possivelmente, esse formato de documentário tem proposto, no cinema nacional, a diversificação da temática LGBT e afins. É um ato político, pois o protagonista Syllvio confronta o mundo por ser diferente.

Como representação flexível do sujeito, passagens em fluxo alternam a identidade sexual, social e de gênero do protagonista na narrativa. O(a) es- 
pectador(a) acompanha e se aproxima de algumas informações e dificuldades enfrentadas pelo personagem. A questão da transexualidade torna-se um assunto controverso e delicado que precisa ser visto/lido para além do corpo, da sexualidade e do gênero. São pessoas que atravessam a fronteira e não podem ficar presas aos ambientes de dor, sofrimento, intolerância, estigma, discriminação e/ou preconceito. $\mathrm{O}$ universo Trans prolifera uma diferença inquietante aos olhos alheios. O(a) outro(a) visualiza Syllvio Luccio na sua expressão transexual sendo filmada pela câmera.

E o enredo desse documentário inscreve situações inusitadas de questões colocadas para o público, de algum modo, pensar. Também demonstra valores contemporâneos sobre família, maternidade, casamento, genética, sexualidade, entre outros, em especial no contexto tradicional e conservador (cultura patriarcal dominante e opressora), no interior da região Nordeste do Brasil.

De acordo com a artista performática e transexual Claudia Wonder

[...] homens efeminados e mulheres masculinas têm seu papel social definido em muitas culturas. Em tais culturas, que sabiamente vivem de acordo com a natureza, ter um corpo com "dois espíritos" não é deformidade e nem motivo de vergonha. Pelo contrário: é sinal de refinamento espiritual. Devido à dualidade sexual, esses povos acreditam que as pessoas trans têm uma visão mais abrangente das coisas. (Wonder, 2010: 290).

Isso configura uma capacidade de mudar. Alterar estados. Por assim dizer, a orientação sexual de qualquer sujeito não deve ser confundida com opção sexual. Não se trata apenas de preferência ou atração sexual, nem no cinema nem na sociedade. A especificidade da natureza humana no Nordeste enuncia uma vida diferente, com suas raízes na cultura regional, sobretudo as contradições da masculinidade e regionalização. Articula-se um jogo coeso de ações sociais. Os processos biopsicossociais ampliam a condição adaptativa do desejo e suas intersubjetividades, para além de uma mera escolha particular como decisão do sujeito, com perdas e ganhos. Por isso, a sociedade deve pressupor a dignidade da diversidade cultural/sexual (Trevisan, 2000).

Da materialidade do corpo à sua performance, há um território fecundo no desempenho das ações intersubjetivas do sujeito nesse audiovisual. A exterioridade do corpo - que não se enquadra nas convenções sociais - programa uma infinidade de situações, na combinatória da lógica da aparência junto à interioridade. O corpo se estabelece como morada - depositário de informação - e sustenta emblematicamente a razão de Ser/Estar, mais que o existir. É convocar um "novo/outro" pensar acerca do sujeito em uma articulação híbrida, (de)marcada pela permutação de vestígios. Dessa forma, a presença do corpo transexual torna-se uma citação culturalmente (des)naturalizada quando repetida à exaustão pelo próprio sujeito. 
Ainda que a transexualidade female to male (FTM) possa contradizer a aparência, Syllvio toma hormônios por conta própria. Seu corpo sofreu algumas a(du)lterações, como a barba e o bigode que cresceram junto com o cabelo, de corte curto, puxado para trás. Isso indica o formato do rosto, como retrato convencional de um homem comum. O tratamento hormonal provoca mudanças físicas que ocorrem aos poucos. Ao resenhar sobre documentários LGBTs, Berenice Bento afirma

A norma de gênero estabelece que somos determinados por nossas estruturas biológicas. [...] As normas de gênero distribuem os corpos em função da normalidade que eles apresentem. Quanto maior o desvio da norma, maior o castigo. Os documentários [LGBTs] apontam exatamente a capacidade de as normas de gênero definir os lugares, as falas os gestos possíveis e impossíveis. (Bento, 2008:256).

O biopoder compreende um fluxo de agenciamento/negociação capaz de lidar com a diferença. Cada sujeito tem direito de Ser/Estar em sua plenitude, de se sentir bem. O que esse filme traduz é uma vontade particular de Syllvio na procura da felicidade, ao exemplificar outros problemas e enfrentamentos relativizados como fragilidades humanas - algumas doenças específicas, por exemplo - ao longo do roteiro.

Há uma enorme expectativa da diversidade cultural/sexual como tema do cinema nacional, ${ }^{1} \mathrm{em}$ particular no documentário. Um conjunto de variáveis estende o avanço de alternativas num sintomático processo camaleônico que tange à condição humana. Indubitavelmente, essa discussão sobre a diversidade cultural/sexual insere o cinema contemporâneo em uma extensão propositiva e amplia a dinâmica do corpo e sua performatização pública, cujo posicionamento ideológico se programa a partir dos enlaces que, na condução da narrativa, apostam na novidade.

Tal discurso cinematográfico potencializa uma (des)construção identitária e performática de grupos e classes sociais marginalizados da periferia em uma intenção extrafílmica a propor uma política do afeto. Na cadência rítmica de imagem/som, devem-se considerar os enlaces estéticos dessa política do afeto que despertam efeitos emblemáticos do corpo e da personalidade do(a) outro(a), os quais apostam na tônica da diversidade, da diferença e da alteridade. Todavia, uma escritura refina e sugere, poeticamente, o afeto para além de encontro, despedida, desejo, erótica, sensualidade, sexo etc. Um breve passeio orgânico absorvido pelo documentário, em sua pluralidade, expande derivativas intersubjetivas (Pelbart, 2013).

1. Ainda mais diante da contribuição significativa do Festival Mix Brasil de cultura da diversidade. Embora destaque, também, as dificuldades de apoio e/ou fomento. 
Há um trecho do filme em que o protagonista caminha sozinho pela estrada deserta. Em plano geral, configura-se a grandeza de uma cena aberta. É dia e o sol aparece refletido no vapor que sobe do asfalto, criando determinado efeito visual impactante que assola o olhar do(a) espectador(a). O clima da cena pede renovação. É a sensação de uma imagem se dissolvendo, ao longe, em estado líquido - uma quase-poética aparece na tela do cinema como elemento imagético que não se apreende, de fato. Ao fundo sonoro, uma secretária eletrônica capta a voz de Syllvio Luccio em uma ardente declaração apaixonada:

Oi meu amor... vontade de lhe cheirar, de lhe agarrar. Fazer amor com você. Te possuir todinha. Pegar seu corpo, jogar em cima dessa cama. Beijar você todinha do pé à cabeça. Deixar você toda arrepiadinha de tesão. Estou louco de saudade, estou tarado... morrendo de vontade... de possuir você todinha, daquele jeito gostoso que só a gente sabe fazer.

As peculiaridades vivenciadas diante da câmara esboçam fragmentos intrigantes da realidade de Syllvio Luccio. Mais que isso, tais peculiaridades enunciam alguns dilemas do protagonista. Verifica-se uma solidão neste documentário, uma vez que a estrada vazia remete ao estar só, falar só. Relatar para o vazio como quem diz alto para si. O documentário contemporâneo provoca uma reflexão que circunda os vínculos sentimentais. Afeto, aqui, serve como tônica para se pensar intensidade e leveza juntos na cena, ao aproximar sujeitos desconhecidos por circunstâncias cruciais de resignação. Entre amizade e amor, seria a ternura em um espaço relacional. O que se aproxima de afeição, apego, complacência estima. Relação. Afetar o(a)outro(a) conforme a realidade tange a um "novo/outro" viver. Mexer. Fazer a coisa acontecer. Um movimento de acolhida cria proximidade, intimidade e privacidade. Cumplicidade de uma condição adaptativa emociona o(a) outro(a) pela incomensurabilidade dos fatos.

\section{Considerações finais}

$\mathrm{Na}$ emergência do debate, o dilema seria experimentar, talvez, aquilo que se estabelece como novidade, visto que está por vir - como constelação de ideias a serem desenhadas, confabuladas. Por isso, não vale a pena se fechar para o que a novidade conclama e tenta instaurar. Em outras palavras, o filme tem seu fio condutor aberto às novidades, o que possibilita, na maioria das vezes, diferentes proposições e caminhos a se entrecruzarem. Sem restringir a criação no campo cinematográfico, a diversidade solicita sua própria emergência. A prática cinemática, por assim dizer, requer expressivo investimento na criatividade a expor os Direitos Humanos. 
Se a proposta do filme é abordar as "novas/outras" transformações sobre a transexualidade, o personagem tenta obter o controle corporal, cujo domínio indica algo de quem sabe, de fato, o que está fazendo, em cada detalhe destrinchado. De maneira irresistível, Syllvio Luccio transpõe para seu corpo, primeiro, o uso do figurino, as vestimentas que dão lugar à mise-en-scène de uma materialidade transexual.

As informações nesse universo Trans impõe ao personagem a sobrevivência no cativeiro corporal, pois se identifica com determinada feição de homem, com estereótipos de gestos grosseiros. Verifica-se uma contradição na busca desse modelo falido da convenção social (de macho), isto é, o padrão hegemônico ultrapassado do poder heteronormativo, falocrático, do varão, patriarcal. Repete o mainstream, porque copia o que já está posto. Este protagonismo seria um possível personagem no cinema atual, em que o(a) espectador(a) acompanha a saga de amores, fracassos, distâncias.

Multiplicam-se os entornos na sociedade em que se estabelece a versatilidade do olhar para uma perspectiva contemporânea, a qual compõe uma maneira diferente. Uma projeção identificatória no cinema aproximaria e alicerçaria uma (re)dimensão mais afetiva e efetiva do espaço intersubjetivo, mediante as relações. A predicação, então, torna-se um convite à abertura do olhar; o que parece ser inevitável.

Para finalizar, gosto desse documentário como ideal de estratégias discursivas porque faz um afrontamento ao canônico a engendrar a diversidade. Como uma espécie de ornamento, esse road movie retira o personagem da margem e o coloca no centro do debate atual. E, desse modo, o papel do cinema tenta, sim, atualizar/inovar a temática da diversidade cultural/sexual na agenda da sociedade. Nos limiares dessa película, a diversidade fecunda "novas/outras" resultantes... outros olhares!

\section{Referências bibliográficas}

Baitello Jr., N. (2012). O pensamento sentado: sobre glúteos, cadeiras e imagens. São Leopoldo: Editora Unisinos.

Bauman, Z. (2013). Danos colaterais: desigualdades sociais numa era global. Rio de Janeiro: Zahar.

Bento, B. (2008). Resenha de Borboletas da vida. Bagoas, jan/jun., 2(2): 253257.

Canclini, N.G. (2008). Leitores, espectadores e internautas. São Paulo: Iluminuras: Itaú Cultural. 
Cevasco, M.E. (2003). Dez lições sobre estudos culturais. São Paulo: Boitempo: Unesp.

Cohan, S. \& Hark, I.R. (eds.) (1997). The road movie book. Londres: Routledge.

Eagleton, T. (2012). Marx estava certo. Rio de Janeiro: Nova Fronteira.

Garcia, W. (2013). Um olhar contemporâneo no Brasil: Olhe pra mim de novo. Caderno de estudos culturais, jul./dez., 5(10): 183-194. Campo Grande - MS.

Gumbrecht, H.U. (2010). Produção de presença, Rio de Janeiro: Contracampo.

Hall, S. (2003). Da diáspora: identidades e mediações culturais. Belo Horizonte: Editora UFMG.

Hall, S. (2002). A identidade cultural na pós-modernidade. Rio de Janeiro: DP\&A.

Marinho, C. (2007). Corpo, espaço e criação: poéticas e vivências contemporâneas do espaço. In W. Garcia (Org.), Corpo \& subjetividade: estudos contemporâneos (pp. 223-236). São Paulo: Factash.

Nagib, L. (2012). Além da diferença: a mulher no Cinema da Retomada. Devires, 9(1): 14-29, Belo Horizonte, jan./jun.

Paiva, S. (2007). Um road movie na rota do Sertão-mar. In Araújo et al. (Orgs.), Estudos de cinema Socine (pp. 171-179). São Paulo: Annablume, Socine.

Peixoto, N.B. (2007). Ver o invisível: a ética das imagens. In A. Novaes (Org.), Ética: vários autores (pp. 425-453). São Paulo: Cia das Letras.

Pelbart, P.P. (2013). O avesso do niilismo: cartografias do esgotamento, São Paulo: $\mathrm{n}-1$ edições.

Ramos, F. (Org.) (2005). Teoria contemporânea do cinema. São Paulo: Senac.

Sodré, M. (2014). A ciência do comum: notas para o método comunicacional. São Paulo: Martins Fontes.

Souza, G. (2015). Deslocamento, performance e memória no documentário Olhe pra mim de novo. XXXVIII Congresso Brasileiro de Ciências da Comunicação - Rio de Janeiro, RJ - 4 a 7/9/2015. Disponível em: http: //portalintercom.org.br/anais/nacional2015/resumos/R10-1599-1.pdf

Teixeira, F.E. (2004). Documentário no Brasil: tradição e transformação. São Paulo: Summus. 
Trevisan, J.S. (2000). Devassos no paraíso: a homossexualidade no Brasil, da colônia à atualidade, 3. ed. Rio de Janeiro: Record.

Vargas Llosa, M. (2012). La civilización del espetáculo, Buenos Aires: Aguilar, Altea, Taurus, Afaguara.

Wonder, C. (2010). Criando gênero, fazendo história. In H. Costa et al. (Org.), Retratos do Brasil homossexual: fronteiras, subjetividades e desejos (pp. 283-291). São Paulo Edusp: Imprensa Oficial.

\section{Filmografia}

Olhe pra mim de novo (2010) de Claudia Priscilla e Kiko Goifman. 